\title{
A União Africana e o Burundi: a busca por novas alternativas na resolução de conflitos no continente africano
}

\section{Érica Araripe ${ }^{1}$, Gabriele Brito ${ }^{2}$, Igor Fernandes ${ }^{3}$, Juliana González ${ }^{4}$, Karine Barcelos ${ }^{5}$,

\author{
Ruan Melandres ${ }^{6}$
}

\section{Resumo}

Esse artigo examina a intervenção da União Africana (UA) no Burundi, em 2003, a partir da análise dos interesses comuns identificados entre os Estados africanos. Analisamos o desenvolvimento da UA e também como a instituição desempenhou um papel interveniente no caso, representando um espaço de convergência entre atores estatais, e obtendo em sua missão AMIB (African Mission in Burundi) resultados como a redução de custos de transação, diminuição de assimetrias de informação e modificação dos cálculos de vantagem feitos pelos Estados envolvidos. Concluímos que a União Africana representa uma nova fase de busca por maior autonomia por parte do continente africano em relação à resolução de conflitos no continente. $O$ presente estudo sugere a abertura de caminhos para análise de posteriores posicionamentos da UA em questões semelhantes.

\section{Palavras-chave:}

Burundi, União Africana, institucionalismo neoliberal, interesses

\section{Abstract}

This article examines the African Union's (AU) intervention in Burundi, in 2003, departing from the analysis of the common interests identified amongst African States. We analyze the development of AU and also how the institution played an intervenient role in the case, representing a convergence space among state actors, and achieving results with its mission AMIB (African Mission in Burundi) such as: reduction of transaction costs, lowering of information asymmetries and modification of advantage calculations made by the States involved. We finish by saying that the African Union (AU) represents a new phase of searching for more autonomy by the African continent when it comes to conflict resolution in the continent. The present study suggests the opening of paths to the analysis of other AU stances concerning similar questions.

\footnotetext{
${ }^{1}$ Bacharel em Relações Internacionais pela Puc-Rio (2013). E-mail: erica.araripe@ gmail.com

${ }^{2}$ Bacharel em Relações Internacionais pela Puc-Rio (2013). Assistente de Previsão Supply Chain Michelin. E-mail: gabriele.oliveira@br.michelin.com

${ }^{3}$ Bacharel em Relações Internacionais pela Puc-Rio (2013). Gestor de Redes do Fundo Brasileiro pela Biodiversidade (FUNBIO). E-mail: igorventura16@hotmail.com

${ }^{4}$ Bacharel em Relações Internacionais pela Puc-Rio (2013). E-mail: julianalgonzalez@ hotmail.com

5 Bacharel em Relações Internacionais pela Puc-Rio (2013). Analista de Comunicação e Redes Internacionais no Fundo Brasileiro para a Biodiversidade (FUNBIO). E-mail: karinebarcelos@yahoo.com.br

${ }^{6}$ Bacharel em Relações Internacionais pela Puc-Rio (2013). Funcionário do Departamento Jurídico da Shell Brasil Petróleo Ltda. E-mail: Ruan.Santos@shell.com
} 
CADERNOS DE RELAÇÕES INTERNACIONAIS, v. 7, n. 1, 2014

Key-words:

Burundi, African Union, neoliberal institutionalism, interests 


\section{Introdução}

Temos por base a análise da atuação da União Africana no caso do Burundi, em 2003. Nesse contexto, vemos que o país sofria com um conflito étnico entre tutsis e hutus, que desestabilizou toda a região dos Grandes Lagos. Com isso, a União Africana, recémcriada em 2002, adentra no país com a missão de estabilizá-lo para um posterior ingresso da ONU na região, com o objetivo de finalizar a missão.

Desde a sua independência, em 1962, o Burundi enfrenta diversos conflitos entre suas etnias. O país é composto por tutsis (cerca de 15\%) e por hutus (cerca de 85\%). Apesar de serem a minoria, os tutsis quase sempre estiveram no poder do país, o que ocasionou inúmeros confrontos entre ambas etnias. O conflito se agravou ainda mais após o assassinato do primeiro presidente hutu, Melchior Ndadaye, em 1993, realizado por facções das forças armadas tutsi, que passou a ser rotulado, por alguns, como um genocídio (U.S. DEPARTMENT, 2008; SVENSSON, 2008, p.8).

Em junho de 1998, o então presidente da Tanzânia, Nyerere, decidiu acabar com os conflitos étnico-políticos na região. Ele começou, então, a mediar as negociações de Arusha, que se estenderam até 2000 e acarretaram no "Acordo de Paz e Reconciliação de Arusha" (NIJIMBERE, 2009, p.2; INTERNATIONAL CENTER FOR TRANSITIONAL JUSTICE, 2008, p.1). Este, porém, não acabou com o conflito ou mesmo conseguiu estabilizá-lo (SVENSSON, 2008, p.12).

Segundo este acordo, o governo do Burundi deveria solicitar a intervenção da força de paz da ONU no país. Porém, em 2002, foi assinado um acordo de cessar-fogo entre diversos grupos rebeldes, no qual ficou estabelecido que a intervenção no país deveria ser uma "missão africana", o que levou a uma missão da União Africana no Burundi em 2003 (SVENSSON, 2008, p.12).Esse apoio dado pela Missão Africana no Burundi é amplamente visto como uma missão de sucesso (HANSON, 2009).

Por se encontrar na região dos Grandes Lagos e próximo a países como Ruanda, Tanzânia e República Democrática do Congo, o conflito no Burundi acabou obtendo uma gravidade muito maior, se estendendo aos demais países da região, gerando grande instabilidade e se tornando de grande importância para as relações internacionais (SVENSSON, 2008, p.8-9).

O caso de intervenção da União Africana no Burundi, em 2003, mostra-se de grande relevância para as Relações Internacionais, pois apresenta uma nova alternativa para a maneira de fazer política no continente africano, ou, ao menos, um esforço nesse 
sentido. Do ponto de vista institucional, a UA significa uma tentativa de identificação de interesses comuns entre os atores e uma organização mais eficiente e legítima desses. Do ponto de vista geopolítico e estratégico, o Burundi localiza-se em uma região importante na África, onde a estabilidade sempre pareceu um ideal distante. A fronteira com o Congo e Ruanda, países cujo cenário de conflitos parece constante, faz do Burundi um territóriochave na tentativa de estabilizar a região e, com isso, proporcionar benefícios relacionados a questões econômicas, políticas e sociais para todo o continente.

Procuramos, então, analisar por que a União Africana, em sua intervenção no Burundi em 2003, obteve uma estabilização do país para a entrada da ONU em seguida. Analisamos principalmente a questão da convergência de interesses, nesse contexto, que foi essencial para o sucesso da missão.

Partimos da hipótese de que as instituições, nesse caso, a União Africana, de fato contribuem para a harmonização dos interesses comuns dos Estados em meio a um ambiente anárquico, por meio, por exemplo, da redução dos custos de transação e do aumento do fluxo de informações entre os membros, favorecendo assim uma futura cooperação entre os Estados-membros destas.

Temos como principal objetivo analisar a intervenção feita no estado do Burundi pela União Africana (UA) dentro da dinâmica do institucionalismo neoliberal. A estrutura adotada parte de uma introdução do conflito analisado e uma breve introdução teórica. Em seguida é apresentado o argumento central baseado na ação da instituição (UA) e suas repercussões.

É utilizado como lente de análise o institucionalismo neoliberal. Para explorar melhor a dinâmica de cooperação pelo canal institucional e o funcionamento desta dinâmica de cooperação racional, adotamos esta linha teórica como melhor ferramenta. É importante ressaltar um posterior desenvolvimento teórico no corpo da introdução.

Acreditamos que a partir de uma análise dentro do institucionalismo neoliberal uma maior estabilização do Burundi foi obtida pelos esforços da organização (UA) e a cooperação de seus estados. Esta foi necessária para uma posterior intervenção da ONU, que buscou trazer um desenvolvimento mais aprofundado na região, mas que não entra na exemplificação teórica - prática abordada no artigo.

De acordo com o institucionalismo neoliberal, tendo por base o livro "After Hegemony" de Robert O. Keohane, o surgimento das instituições pode ser explicado por meio da função que elas exercem. Ou seja, o surgimento das instituições se dá por meio 
da necessidade de ajustes a uma situação de discórdia de modo a promover a cooperação, operando como variáveis intervenientes entre essas duas situações. É relevante destacar aqui a definição de Krasner para regimes, estes seriam um conjunto implícito/explícito de princípios, normas, regras e procedimentos decisórios em torno dos quais as expectativas dos atores convergem (KEOHANE, 1984, p.57).

Primeiramente, é necessário distinguir três situações distintas, a harmonia, a discórdia e a cooperação. A harmonia é a realização automática dos interesses, situação na qual o interesse de um ator não entra em choque com o de outro, entretanto essa situação não se apresenta na realidade. Na discórdia, a busca dos interesses individuais não facilita e até impede a realização dos interesses dos demais, fazendo-se necessário um ajuste de interesses. Este, quando gera uma compatibilidade de políticas, torna possível a cooperação - aqui entendida como diminuição da discórdia no sistema internacional (KEOHANE, 1984). A UA tornou possível para os estados africanos compatibilizar políticas focando em questões de interesses comuns como uma intervenção no Burundi a fim de estabilizar a região.

Para o surgimento do regime não é necessária a existência de um hegemon, basta que exista um grupo pequeno com interesses comuns. O grupo pequeno será mais eficiente que um grande na medida em que há um relacionamento mais próximo entre os atores, o que estabelece maiores laços de confiança além de tornar mais fácil a aplicação de incentivos seletivos, sejam eles positivos ou negativos. Além disso, num grupo pequeno, a participação de todos é necessária para a produção do bem coletivo, no caso da UA o desenvolvimento do continente africano; assim, se um dos membros não arca com sua parte nos custos, torna notoriamente mais pesado o arcar dos custos para os demais, o que dificulta enormemente a existência de "free riders". Estes custos são os custos de transação e incluem, por exemplo, os custos de informação que são bastante elevados, são um grande entrave a cooperação e às vezes insuportáveis para alguns atores que tentem arcar sozinhos. Com a perspectiva de uma cooperação no longo prazo, os atores preocupam-se em estabelecer uma boa reputação o que é feito por meio da cooperação constante. Em outras palavras, a situação torna-se um jogo iterado no qual a expectativa de um reencontro aumenta a sombra do futuro, o modo como os atores valorizam as interações futuras, requisito necessário para a estabilização da cooperação. Ou seja, o monitoramento dentro de uma instituição é feito de uma forma mais fácil o que 
reduz a insegurança dos atores em cooperar e como exemplo empírico tem se a aproximação entre os estados africanos (KEOHANE, 1984).

Os regimes são capazes de ajudar na solução de problemas que dificultam a cooperação, tais como os custos de transação, problemas de coordenação, a incerteza e assimetria de informação; o fazem por meio da provisão de informação, estabilização de expectativas e alteração do padrão de custos das interações. Os atores são responsáveis pela instituição do regime mas, ao mesmo tempo, estão sujeitos aos constrangimentos estruturais impostos por eles. Em sua atuação como variáveis intervenientes no relacionamento dos atores, afetam o contexto de escolha destes influindo no horizonte temporal e nos mecanismos que afetam escolhas provendo certa ordem (KEOHANE, 1984, p.244-246).

Esses conceitos aqui evidenciados serão cruciais para a compreensão dos processos analisados ao decorrer do artigo. Com essa introdução teórica será possível analisar o caso do Burundi dentro de uma lente teórica já apurada e detalhar os processos os quais levaram a cooperação dos atores nesse tema específico.

Utilizamos nesse artigo o método qualitativo e, por meio do estudo de caso, analisamos tal situação. Utilizamo-nos também do método de rastreamento do processo (process tracing) para ter uma visão mais aprofundada do caso. Nessa obra, tornam-se visíveis as variáveis envolvidas na construção do artigo, sendo a variável independente os interesses comuns dos países integrantes da União Africana, a variável dependente os resultados da ação da UA no Burundi e a variável interveniente as instituições em si.

Este artigo está estruturado em cinco sessões: a introdução, uma sessão sobre a convergência dos interesses dos atores da UA, um estudo mais aprofundado sobre a OUA e a UA, os resultados obtidos com a intervenção da UA no país e a conclusão do caso.

\section{Os Interesses Comuns dos Estados}

A existência de interesses comuns, ou o adensamento da agenda temática, é um fator importante que pode levar à ocorrência de cooperação entre os estados. Esta é dada pela estrutura de pay-offs e pela percepção dos atores com relação às ações dos demais. Analisando-se os incentivos dos atores, vemos que as instituições são criadas com o objetivo de aumentar o bem-estar de seus criadores. Em suma, as instituições são um 
produto dos interesses dos estados, sendo criadas propositalmente por atores que partilham de objetivos comuns específicos (KEOHANE, 2005).

Houve uma mudança de interesses na transição da Organização da Unidade Africana para a União Africana, em 2002; apesar de ambas terem em comum a busca pela paz e pela segurança, a OUA focava no combate ao apartheid e à colonização, enquanto o espectro de interesses da UA era mais amplo, abrangendo, além de segurança, outros aspectos como a busca pela cooperação política e econômica entre os estados-membros e a promoção da democracia e do respeito aos direitos humanos (SVENSSON, p.9-10).

Uma importante mudança foi o relaxamento das premissas da soberania, com a implementação do "rules of engagement", que consistia na permissão por parte da União Africana do uso da força no caso de um agravamento dos conflitos no continente. Isso reflete o interesse comum dos estados-membros em "soluções africanas para problemas africanos", isto é, a instituição torna-se capaz de estabelecer missões de paz no continente africano quando a ONU não desejar ou não for capaz de se envolver no conflito (SVENSSON, p.19).

A partir da convergência de seus interesses, os atores criaram uma instituição que os ajudava a alcançar tais interesses, e para se fazer parte desta devia-se compartilhar de certos valores comuns, no caso, os valores democrático-liberais. Nesse contexto, os membros dessa instituição acabaram por absorver tais valores e os interiorizaram dentro da estrutura do Estado. A relação instituição-estado é direta, sendo que um depende do outro, compartilhando valores e interesses (KEOHANE, 2005).

A União Africana (UA), como instituição, serviria então para garantir o cumprimento das responsabilidades assumidas pelos Estados-membros, para legitimar as ações por ela exercidas, aumentando a credibilidade frente ao ocidente, e para aumentar a informação que circula entre os membros desta, gerando assim, um aumento da confiança entre os Estados-membros (KEOHANE, 2005, p.85-109).

A região dos Grandes Lagos, na África Central, sempre foi de grande importância econômica, uma vez que é uma região rica em minérios, como cobalto e diamantes. Esta área é composta pelo Burundi, República Democrática do Congo, Quênia, Uganda, Ruanda, Tanzânia, Zâmbia, Malawi e Moçambique. Além disso, nessa região, há um grande fluxo de tutsis e hutus, duas etnias envolvidas num conflito que dura anos. Logo, a estabilização do Burundi representaria um importante passo para a resolução do conflito étnico na região. Fica, então, clara a crença dos estados membros da União Africana de 
que a segurança de um país depende da segurança dos demais e, advindo disto, há o interesse em estabilizar os outros países (TIEKU, 2004).

A segurança no continente africano, encarada como uma situação de interligação entre os Estados é um estímulo à busca por soluções para o conflito no Burundi e, consequentemente, para as disputas étnicas entre tutsis e hutus na região dos Grandes Lagos. Além disso, era essencial, dentro do arcabouço institucional da União Africana, a promoção dos direitos humanos, constantemente violados durante os conflitos. Paralelamente, há um adensamento claro da agenda e as questões de segurança podem ser entendidas como um fenômeno de interdependência no qual uma área impacta as demais, por exemplo, uma questão da área de segurança que tem efeitos sobre a econômica (TIEKU, 2004).

Os principais objetivos da União Africana dentro do país, inicialmente, eram: (1) servir como intermédio entre as partes em conflito, promovendo um ajuste de interesses e um maior entendimento entre tais partes; (2) implementar e monitorar os acordos de cessar-fogo; (3) prover e facilitar a assistência ao desarmamento no país; (4) facilitar a ação humanitária dentro do país, o que ajudaria principalmente aos civis e; (5) coordenar as missões da ONU dentro do país (SVENSSON, 2008, p.11-12).

Entre os países africanos, especialmente África do Sul e Nigéria, havia uma grande preocupação com relação à atração de investimentos estrangeiros para o continente africano, uma vez que isto seria fundamental para a modernização da região e consequente aumento de importância no comércio mundial. Para tal, era necessário transformar a imagem do continente frente ao Ocidente, isso foi realizado por meio da promoção dos valores democrático-liberais, o que foi feito em meio a uma onda de panafricanismo. O desenvolvimento econômico do continente era um interesse comum das nações africanas e a promoção desses valores fazia parte da estratégia para alcançar esse objetivo (SVENSSON, 2008, p.17).

O pan-africanismo e a promoção de valores democrático-liberais, ao mesmo tempo em que formularam o discurso de criação da União Africana, informaram profundamente as ações desta, como é possível perceber pelo estabelecimento da missão no Burundi, onde esses valores foram, de fato, promovidos. O pan-africanismo foi, de certo modo, um meio que ajudou os estados africanos a reconhecerem a importância de uma instituição continental que serviria como ferramenta para alcançar os próprios 
interesses nacionais, tendo em vista a coordenação de expectativas e a harmonia de interesses gerada pela promoção desse valor (TIEKU, 2004, p.267).

Diversos fatores ajudam a compreender a ação da União Africana na missão “AMIB”, tais como: (1) estabelecer a paz e a estabilidade na área dos Grandes Lagos, importante região comercial do continente, sendo o Burundi um dos países centrais de tal região; (2) a questão da responsabilidade pela manutenção da paz e da resolução de conflitos da UA dentro do continente, reconhecendo seu direito de intervenção em casos mais graves; (3) líderes de muitos países africanos, principalmente da África do Sul, viram tal conflito como uma oportunidade da Organização Pan-Africana demonstrar sua separação da OUA e se mostrar inserida na agenda de paz e segurança do continente africano; (4) os líderes africanos desejavam mostrar à comunidade internacional que um desastre, como o ocorrido em Ruanda, não se repetiria no Burundi (SVENSSON, 2008, p.19-20).

Em suma, a criação da UA foi pautada pelos interesses comuns dos atores, estados africanos, que eram o desenvolvimento econômico do continente e uma maior participação no cenário mundial, permitindo que os objetivos dos estados membros sejam mais facilmente atingidos. A participação dos estados na instituição levou à internalização dos valores democrático-liberais e do conjunto de ideias do pan-africanismo, o que refletiu bem na intervenção humanitária no Burundi, em 2003. Solucionar a crise no Burundi era do interesse dos estados-membros da instituição, uma vez que representaria um avanço importante para a solução de uma crise maior na região dos Grandes Lagos. Estavam envolvidos na ação interesses econômicos, humanitários e, é claro, de segurança.

\section{A União Africana (UA)}

\section{O Pan-Africanismo}

Considerando o fato de que regimes internacionais possuem valores potenciais além de seus objetivos concretos, os quais pautam a interação dos atores e colaboram para uma convergência de expectativas (KEOHANE, 1984, p.247), podemos identificar, ao longo do processo de formação da União Africana (UA), a presença de um valor-chave: o panafricanismo. Este foi crucial para a harmonização de interesses dos Estados envolvidos, por isso permeará toda a discussão a seguir, destacando-se como um elemento 
interveniente fundamental para a compreensão da instituição abordada neste artigo em maior profundidade.

A evolução do movimento pan-africano tem muito a dizer a respeito da emergência da União Africana, pois boa parte deste imprimiu suas lutas e reivindicações, em maior ou menor grau, em normas, regras e princípios constitutivos da UA, os quais serão analisados com mais detalhes posteriormente (MURITHI, 2007, p.1).

Sendo assim, o que é o pan-africanismo e como ele se mostra nessa fase inicial de formação da União Africana? Primeiramente, não há uma definição única a respeito do que venha a ser o pan-africanismo. Muitos são aqueles que falam sobre o tema, assim como variadas são as suas nuances (MURITHI, 2005, p.11; ADI \& SHERWOOD, 2003, p.7).

O surgimento do pan-africanismo relaciona-se intimamente com o imperialismo do final do século XIX. A ideia de Kwame Nkrumah, o primeiro presidente de Gana e cofundador da Organização da Unidade Africana (OUA), tratada em seguida, resumia do que verdadeiramente se tratava o movimento: "A África deve se unir ou se desintegrar individualmente". Ou seja, historicamente, o pan-africanismo é a percepção dos africanos na diáspora e no continente, que eles compartilham objetivos comuns (MURITHI, 2005, p.11).

A luta por igualdade social e política, pela liberdade de exploração econômica e o fim da cultura de dependência externa eram temas nos quais havia um encontro de interesses; um apelo a maior solidariedade entre os povos africanos era percebido como vantajoso para os Estados envolvidos. A partir desse momento, um esforço de institucionalização se viu necessário, o qual teve início com a criação do Congresso Panafricano, no início do século XX, seguido pela Organização da Unidade Africana (OUA), em 1963 e pela União Africana, em 2002 (MURITHI, 2005, p. 21; OKHONMINA, 2009, p.88).

\section{A Organização da Unidade Africana (OUA)}

Na primeira metade da década de 1960, o surgimento de novos Estados no continente africano dificultou ou, mesmo, impossibilitou que o pan-africanismo fosse visto como um movimento de integração, acelerando o movimento de liberalização colonial. Enquanto os governos dos novos países africanos discordavam sobre como a política de integração deveria ocorrer, reconheciam conjuntamente o imperativo de 
eliminação do colonialismo que ainda assolava o continente. Tal ideal era defendido, especialmente, por Libéria e Marrocos, ambos defensores da descolonização e da política de não-alinhamento (WAPMUK, 2009, p.651).

Este comprometimento com a causa da descolonização foi um dos principais motivos, se não o principal, a levar ambos os Estados a liderarem um esforço para a criação da Organização da União Africana (OUA), em um encontro em Addis Ababa, Etiópia, em 1963, com a presença de parte dos Estados africanos (CHANAIWA E KADJO, 1999, p. 748).

Interesses compartilhados revelaram-se cruciais para a formação de um regime internacional como a Organização da Unidade Africana (OUA). Ou seja, esses mesmos interesses partilhados, principalmente, por Monrovia e Casablanca, os quais se encontravam em pólos opostos, atuaram como incentivos não só para aproximar ambos os Estados, mas, também, para promover uma convergência de interesses no continente (ver KEOHANE, 1984, p.79).

A instituição, estabelecida em 1963, fundamentou sua atuação no continente de acordo com os seguintes princípios: soberania dos Estados; a não-interferência nos assuntos domésticos dos Estados-membros; respeito à soberania e à integridade territorial de cada Estado bem como seu direito de existir; a resolução de disputas entre os membros deveria ocorrer por meio de negociação, mediação, arbitragem ou conciliação; condenação sem reservas de assassinatos políticos e de atividades subversivas por parte de seus membros; busca pela liberalização dos territórios africanos ainda não independentes; e afirmação de uma política de não alinhamento em relação aos blocos capitalista ou socialista (POWELL, 2005, p.10; CHANAIWA \& KODJO, 1999, p.749).

O surgimento da Organização da Unidade Africana (OUA) representa a segunda tentativa de institucionalização do pan-africanismo. Entretanto as divergências entre seus membros sobre questões de revisão ou não de fronteiras paralisaram a instituição. Desta forma, a organização ficou incapacitada de exercer influência nas políticas nacionais, de monitorar o comportamento interno de seus Estados-membros e, até mesmo, de prevenir que atrocidades relacionadas aos direitos humanos fossem cometidas. Dessa forma, a Instituição passou a ser vista como um "Clube de Líderes Africanos", onde alguns dos quais sequer haviam sido eleitos pelo seu povo, não passando, portanto, de uma organização de ditadores ou de meras oligarquias (MURITHI, 2005, p.26-27). 


\section{A emergência da União Africana (UA)}

Com o fim da Guerra Fria, a ineficácia da Organização da Unidade Africana tornou-se ainda mais evidente. Como visto anteriormente no processo de institucionalização do pan-africanismo, a instituição mostrou-se pouco capaz em alcançar os valores pan-africanos, os quais eram conjuntos de interesses mútuos pré-estabelecidos pelos próprios Estados, demonstrando pouca habilidade em lidar com conflitos continentais e mobilizar, de fato, uma ação conjunta com os Estados-membros. Além dos efeitos da Guerra Fria, outros elementos tiveram um papel importante no processo de transformação institucional: a influência de novas ideias de modernização advindas de uma nova ordem que se estabelecia no Sistema Internacional e a prejudicial presença de elites que dominavam as políticas no âmbito da Organização da Unidade Africana (OUA) (TIEKU, 2004, p.252). Percebeu-se que uma transferência sistêmica, ou seja, uma alteração nas relações globais de poder deu origem a novos padrões de interdependência e a emergência de novos interesses (ver KEOHANE, 1984, p.108).

Alguns líderes assumiram projetos de reforma da Organização da Unidade Africana (OUA), realizando novos cálculos de vantagem e entendendo que os interesses comuns entre os Estados precisavam de um novo arcabouço institucional. O Estado que mais se destacou na busca por mudanças foi a África do Sul, com o Congresso Nacional Africano (ANC, em inglês) personificado pela figura de Nelson Mandela, então presidente (1994-1999). As reivindicações trazidas à tona por Mandela, como a defesa dos direitos humanos, a promoção da democracia e o liberalismo econômico, ganharam ainda mais força quando Thabo Mbeki assumiu a presidência em 1999. Este buscava, além do que foi proposto por Mandela, recriar os ideais pan-africanos na forma de um conceito conhecido como Renascença Africana, o qual fornecia uma estrutura normativa para uma abordagem que, entre outros objetivos, primava pela construção de uma identidade africana condizente com seu projeto para a África do Sul, o qual acabara refletindo fortemente no modelo de reforma para a Organização da Unidade Africana (OUA) (TIEKU, 2004, p.253-255).

Outro líder cujas ideias foram essenciais para o processo de transformação da Organização foi Olusegun Obasanjo, presidente da Nigéria (1999-2007). Suas principais ideias giravam em torno de um melhor gerenciamento institucional de áreas como segurança, estabilidade e desenvolvimento dentro do continente. O incentivo aos acordos comerciais e a política liberal fazia parte de um esforço para a redução de custos de 
transação dentro do regime, buscando superar vários aspectos problemáticos característicos das economias africanas (TIEKU, 2004, p. 256-257; ADEJO 2001, p.121122).

Destaca-se, ainda, a importante participação do governo de Muammar Ghaddafi (1998 - 2011), em sua tentativa de estabelecer algo semelhante aos "Estados Unidos da África". Tal proposta fora primeiramente concebida em um encontro pan-africano no Cairo, Egito, em 1960, por Kwame Nkrumah, líder da independência de Gana (1957) e, então, grande incentivador do movimento (OKHONMINA, 2009, p.88). No entanto, muitas das sugestões de Ghaddafi estavam embebidas de um interesse geopolítico e estratégico por parte do Estado libanês de se inserir como um ator relevante dentro desse ambiente de mudança da OUA na década de 1990 (TIEKU, 2004, p.260-262; ADEJO, 2001, p.133).

Reunindo as propostas que emergiam por parte desses três líderes principais, em julho e setembro de 1999, os então membros da Organização da Unidade Africana (OUA) estavam presentes, respectivamente, em Argel, capital da Argélia e Sirte, na Líbia;no intuito de adiantar os procedimentos para a reforma da Organização da Unidade Africana. Em julho de 2000, os chefes dos Estados-membros da OUA se reuniram em Lomé, Togo, para estabelecer o Ato Constitutivo da União Africana (UA). No entanto, somente em 2002 a instituição foi lançada formalmente, com a ratificação de dois terços da OUA (ADEJO, 2001, p.133; WAPMUK, 2009, p.655-656).

Portanto, observa-se que a emergência de um novo regime foi facilitada por uma relação estabelecida previamente entre os países membros. Assim, a União Africana (UA) acabou por emergir a partir das estruturas pré-existentes da Organização da Unidade Africana (OUA) (ver KEOHANE, 1984, p.79).

\section{A Atuação da União Africana No Burundi}

A relevância de um regime de segurança ativo para a África vem sendo notada desde o início dos anos 90, quando o fim da Guerra Fria foi um fator chave para o desencadeamento de guerras que se espalharam dentro do continente. A criação de uma resposta mais robusta às diferentes formas e fases de um conflito foi iniciada em 1993, quando a OUA estabeleceu o Mecanismo para Prevenção, Administração e Resolução de Conflitos, cujas funções eram antecipar e prever situações de potencial conflito e, caso 
este se agravasse, mobilizar esforços de peacemaking e peacebuilding. No entanto, o comprometimento da então instituição com os princípios de respeito à soberania e nãointerferência nos assuntos domésticos dos Estados-membros mostrou-se um entrave à atuação efetiva da mesma (POWELL, 2005, p.9-10; ALBERT, 2007, p.47).

A União Africana acabou incorporando tal mecanismo, porém deu-lhe uma nova roupagem, estabelecendo o Conselho de Paz e Segurança (PSC, em inglês). Este provê uma estrutura operacional para a implementação, de fato, das decisões tomadas nas áreas de prevenção de conflitos e operações de paz. A coordenação de esforços continentais, a promoção de paz, segurança, estabilidade e proteção aos direitos humanos fazem parte do órgão cuja agenda contempla variadas áreas (POWELL, 2005, p.9-11; ALBERT, 2007, p.47-48).

Um elemento sempre presente na discussão sobre Operações de Paz está presente também nesse emergente regime de segurança da UA: o termo Responsibility to Protect ou $R 2 P$, o qual impõe importantes limitações à soberania estatal. O Ato Constitutivo da União Africana reconhece, no artigo quarto, que a responsabilidade principal de um Estado é proteger os seus cidadãos, ou seja, a instituição possui o direito de intervir em um determinado território de um país-membro conforme julgar apropriado, a fim de zelar por esse compromisso fundamental. Assim, a UA confere maior legitimidade e efetividade às suas ações no que diz respeito ao gerenciamento de questões de segurança na região, estando claramente à frente de sua antecessora, a OUA, e inaugurando uma cultura de "não-indiferença" (POWELL, 2005, p.10-13; MURITHI, 2007, p.4; HANSON, 2009).

A AMIB, lançada em abril do mesmo ano, foi a primeira operação a ser estabelecida e seu objetivo central era criar condições suficientemente estáveis para que o Conselho de Segurança da ONU autorizasse uma intervenção partindo da mesma. Logo, a AMIB foi lançada com a compreensão de que seria substituída dentro de alguns meses. Outras tarefas designadas eram as seguintes: estabelecer e manter ligações entre as partes; monitorar e verificar a implantação de acordos de cessar-fogo; facilitar e prover assistência técnica aos processos de DDR (Desarmamento, Desmobilização e Reintegração); facilitar a chegada de assistência humanitária (inclusive para refugiados e pessoas internamente deslocadas) e coordenar atividades com a ONU (SVENSSON, 2008, p.11-12; BOSHOFF, 2003, p.3; POWELL, 2005, p.34- 36). 


\section{Resultados obtidos com a intervenção no Burundi em 2003}

A atuação da União Africana no Burundi, em 2003, revela uma nova postura dos países africanos, os quais procuram traçar caminhos mais autônomos ao lidar com dilemas do continente. A relevância política e estratégica da região dos Grandes Lagos foi um ponto de convergência para a atuação da UA. Os interesses mútuos existiam e, por meio da estrutura institucional, eles se converteram em ações coordenadas (SVENSSON, 2008, p.8-9).

Com isso, vemos que o principal objetivo da missão da União Africana no Burundi, que era a estabilização da região para a posterior entrada da ONU na missão, foi alcançado. A supervisão do cessar-fogo e o apoio às iniciativas de desmilitarização também são pontos importantes na primeira intervenção da então recém-criada UA, como a facilitação da negociação entre as partes e da subsequente formação de um governo nacional no país. Tais êxitos se deram à organização por parte da instituição em si, a qual incluía determinação de tarefas específicas e interesses complementares. Para isso, a União Africana utilizou-se de diversos tratados e acordos, a fim de aproximar os Estados envolvidos na questão, fornecendo mais informações sobre quais processos estavam em andamento e quais normas, regras e procedimentos haviam de ser seguidos para o alcance de objetivos pré-determinados pela instituição (FERREIRA, 2005; SVENSSON, 2008, p. 15).

O papel da ONU também se mostrou fundamental para a obtenção de resultados considerados de sucesso. Percebida como uma "missão híbrida", a AMIB foi criada e lançada antes de um cessar-fogo completo e forneceu uma dimensão de segurança para a atuação posterior da ONU (POWELL, 2005, p.34-35).

Como já citado anteriormente, a participação da ONU estava prevista, ou seja, as expectativas nesse caso exercem um papel sem o qual não se pode compreender o porquê dos saldos obtidos na intervenção de 2003. A ONUB (UN Operation in Burundi) foi um exemplo de cooperação entre duas instituições, a ONU e a UA, reforçando a ideia de que instituições internacionais ajudam a perceber os interesses comuns na política mundial. (KEOHANE, 1984, p.284)

Outro ponto importante alcançado pela UA nessa missão foi a questão étnica da região, referente ao conflito entre tutsis e hutus, que teve grande avanço e, com isso, também uma maior estabilização da questão política na área (ADEJO, 2001, p.134-135). 
Em outras palavras, a interdependência político - econômica entre, principalmente, os países da região dos Grandes Lagos, e, em menor grau, porém não menos relevante, entre os países do continente como um todo, criou interesses e estabeleceu vantagens explícitas na cooperação, por esse motivo, a União Africana mostrou-se engajada em defender a promoção de áreas como direitos humanos e democracia no Burundi (KEOHANE, 1984, p. 8).

\section{Conclusão}

Desde a sua independência, em 1962, o Burundi enfrenta diversos conflitos entre as duas principais etnias que lhe compõem, os tutsis e os hutus. Apesar de serem a minoria, os tutsis quase sempre estiveram no poder do país, o que ocasionou inúmeros conflitos entre tais etnias (U.S. DEPARTMENT, 2008; SVENSSON, 2008, p.8). Com o aprofundamento desse conflito, tornou-se necessária a intervenção por parte de instituições internacionais, e nesse caso, a organização que encabeçou a ação na região foi a União Africana (UA).

De 1998 a 2000, ocorreram as negociações do “Acordo de Paz e Reconciliação de Arusha”, que tinham por objetivo acabar com esse conflito étnico/ político presente na região. O conflito continuou a existir após essas negociações, o que fez com que, em 2002, após a ratificação de um acordo entre os Estados da região, ficasse estabelecido que a missão a ser implementada no Burundi deveria ser uma "missão africana", o que levou à primeira intervenção da União Africana no continente, em 2003 (INTERNATIONAL CENTER FOR TRANSITIONAL JUSTICE, 2008, p.1; SVENSSON, 2008, p.12).

A convergência de interesses dos Estados africanos foi um processo o qual acabou por culminar na União Africana, objeto de nossa análise. Essa instituição, cujo princípio do pan-africanismo está em um lugar central, primeiramente, materializou-se na forma de Congressos pan-africanos a partir do início do século XX, onde o cenário de luta contra a colonização mobilizava povos ao longo do continente e também fora dele e, ao longo dos anos se tornava cada vez mais forte, com as reivindicações por independência (MURITHI, 2005, p.23-26).

O próximo passo foi a criação da Organização da Unidade Africana (OUA), nos anos 60, onde muitos Estados da África estavam se tornando independentes e, pouco a pouco, buscando trilhar caminhos de maior autonomia em diversas áreas. Seus principais 
objetivos eram o respeito a soberania e a não-interferência nos interesses domésticos. Estes acabaram por ditar o destino da instituição, a qual revelou-se tremendamente ineficaz em diversos aspectos de gerenciamento das políticas no continente, perdendo, inclusive, boa parte de sua legitimidade pelo fato de haver se tornado um conjunto de meras oligarquias (POWELL, 2005, p.10; MURITHI, 2005, p.26-27).

A demanda por novos regimes mostrou-se bem evidente a partir do final da Guerra Fria, onde diversos fatores foram cruciais para a emergência da União Africana (UA) ou de esforços em direção a novos horizontes institucionais. Alguns Estados influentes na região (Nigéria, Líbia e África do Sul, principalmente) foram centrais para a identificação de interesses mútuos, os quais acabaram por modelar a instituição e seus princípios (TIEKU, 2004, p.242 -255).

Assim, em 2002, com o estabelecimento formal da UA, seus objetivos também foram bem delimitados, por meio de seu Ato Constitutivo, como: maior unidade e solidariedade entre os países africanos; cooperação e integração, por meio da reunião das instituições sub-regionais; criação de condições para que os Estados africanos se engajem em relações sociais, econômicas e políticas de forma a tornar o conflito entre eles menos provável (um tipo de "Concerto Africano") e desenvolvimento de uma estrutura institucional para que os Estados-membros participem de forma mais efetiva no mercado internacional (ADEJO 2001, 134-135; WAPMUK, 2009, p.656-657).

A instituição também partilha de preceitos relacionados a questão do Responsability to Protect, o qual mostra-se fundamental no que diz respeito às intervenções humanitárias da UA no continente. O caso do Burundi, em 2003, com o envio da AMIB (African Mission in Burundi) exemplifica a importância desses princípios e demonstra a disposição e a convergência de expectativas por parte dos países africanos em cooperarem, por meio da UA, em prol de dilemas do próprio continente (POWELL, 2005, p.10-13; HANSON, 2009).

Analisando-se a ação da União Africana (UA) nesse caso, vemos que tal instituição foi essencial para o desenrolar do conflito, sendo responsável pela estabilização da região para que, quando a situação estivesse mais equilibrada, a ONU pudesse adentrar na missão. Para isso, a UA lidou com o arranjo de interesses convergentes (e divergentes) dos Estados africanos envolvidos, realizando negociações e acordos a fim de estabelecer a ordem no local (SVENSSON, 2008). 
Como afirma Robert Keohane, em sua obra "After Hegemony”, as instituições, ou regimes, servem exatamente para esse propósito: convergir os interesses de seus membros, a fim de facilitar a cooperação entre eles. Para tal, as instituições reduzem os custos de transação, aumentam o fluxo de informações entre os Estados-membros e reduzem as incertezas e os riscos. No caso da UA, intervir no Burundi, em 2003, foi parte de uma identificação de interesses comuns entre atores na região e de uma organização institucional que evidenciou as vantagens do esforço cooperativo.

Este artigo também pode iluminar estudos futuros a respeito de instituições africanas e da atuação, efetividade e construção destas, tendo em vista que os países da África estão buscando, cada vez mais, maior autonomia na resolução de conflitos no continente. Seria, então, relevante também analisar, a partir deste artigo, a intervenção da União Africana em Darfur, em 2004. e na Somália, em 2007.

\section{Referências Bibliográficas}

ADEJO, A. From OUA to AU: New Wine in Old Bottles?. African Journal of International Affairs, v.4, nº1 \& 2, p.119-141, 2001

ALBERT, I. The African Union and Conflict Management. Africa Development, v.32, nº 1, p.41-68, 2007

BOSHOFF, H. Burundi: The African Union's First Mission. Institute for Security Studies, Jun, 2003. Disponível em: 〈http://www.iss.co.za/uploads/BURUNDIJUN03.PDF> Acesso em: 18 Out.2010

HANSON, S. The African Union. Council on Foreign Relations, Set, 2009. Disponível em: < http:// www.cfr.org/publication/ 11616/African_union.html> Acesso em: 23 Out.2010

International Center for Transitional Justice. BURUNDI. Submission to the Universal Periodic Review Of the UN Human Rights Council, 2008

KEOHANE, R. After Hegemony: Cooperation and Discord in the World Political Economy. Princeton: Princeton University Press, 1984

KEOHANE, R. International Institutions and State Power: Essays in International Relations Theory. San Francisco: Westview Press, 1989

KODJO, E.; CHANAIWA, D. Pan- Africanism and liberation In: MAZRUI, A. (Ed) General History of Africa.VIII, Africa since 1935. California: University of California Press, 1999, p. $744-766$ 
KUFUOR, K. The Collapse of the Organization of African Unity: Lessons from Economics and History. Journal of African Law, v.49. n², p.132-144, 2005

MOLLER, B. The African Union as a security actor: African Solutions to African problems? Crisis Research Center, London School of Economics and Political Science, v. 2, $\quad$ n. 2009 57, Disponível em: $\langle$ http://www.ccis.aau.dk/digitalAssets/5/5045_bjorn_moller.pdf $>$. Acesso em: 21 Out.2010

MURITHI, T. The African Union: Pan-Africanism,Peacebuilding and Development. Ashgate Publishing, 2005.

NIJIMBERE, L. The Burundi Peace Process In: Insider Mediators: Exploring Their Key Role in Informal Peace Processes. Disponível em: <http://www.berghofpeacesupport.org/publications/MED_Insider_Mediators_Burundi.pdf $>$.

OKHONMINA, S. The African Union: Pan-Africanism Aspirations and the Challenge of African Unity. The Journal of Pan African Studies, v.3, nº4, p.85-100, 2009

POWELL, K. From Promise to Practice: The African Union in Burundi and Darfur In: The African Union's Emerging Peace and Security Regime Opportunities and Challenges for Delivering on the Responsibility to Protect, 2005. http://www.iss.co.za/pubs/Monographs/No119/Mono119.pdf

SVENSSON, E. The African Mission in Burundi: Lessons learned from the African Union's first peace operation.FOI, Swedish Defense Research Agency, Setembro, 2008. Disponível em: 〈http://www.foi.se/upload/projects/Africa/FOI2561_AMIB.pdf > Acesso em: 20 Out.2010

TIEKU, T. Explaining the Clash and Accommodation of Interests of Major Actors in the Creation of the African Union. African Affairs, v.103, nº411, p.249-267, 2004

U.S Department of State. Diplomacy in Action. Bureau of African Affairs. Backgraund notes: Burundi. 4 de Outubro de 2010. Disponível em: 〈http://www.state.gov/r/pa/ei/bgn/2821.htm\#history>.

WAPMUK, S. In Search of Greater Unity: African States and the Quest for an African Union Government. Journal of Alternative Perspectives in the Social Science, v.1, n³, p.645-671, 2009

WILlIAMS, W. Black American Attitudes Toward Africa. Pan African Journal, v.4, n², p.173-194, 1971 